\title{
Type-1 and Type-2 Fuzzy Logic Controller Based Multilevel DSTATCOM Using SVM*
}

\author{
Foudil BENZERAFA, Abelhalim TLEMÇANI, Karim SEBAA \\ Laboratoire de Recherche en Electrotechnique et en Automatique, \\ University of Médéa, Médéa, Algeria \\ benz.foudil@gmail.com, h_tlemcani@yahoo.fr, karim.sebaa@gmail.com
}

\begin{abstract}
DSTATCOM (Distribution Static Compensator) is a shunt device. It is used to solve power quality problems in distribution systems. DSTATCOM is a shunt device used in correcting power factor, maintaining constant distribution voltage and mitigating harmonics in a distribution network. This paper presents a comparison of the performances of Type-1 and Type-2 Fuzzy logic controlled multilevel DSTATCOM for improvement of electric power, and corrects the power factor. The pulses for the five-level inverter are generated by Space Vector Modulation (SVM). The performance of Type-1 and Type-2 fuzzy logic controllers under load variation is evaluate using simulation results in MATLAB/Simulink.
\end{abstract}

Keywords: DSTATCOM; Fuzzy logic controller; Space Vector Modulation (SVM).

\section{Introduction}

Today, due to the rise in large variety of loads which pollute the power system and the use of power semiconductor components that increase power quality problems the maintenance and improvement of power quality in a power system is extremely important [1]. We can reduce the network losses and improve the quality of power by the compensation of reactive power in distribution network [2]. The control of reactive power using DSTATCOM can solve many power quality problems faced by distribution systems [3]. DSTATCOM is a custom power device connected in shunt with the distribution networks. It is used for reactive power compensation, voltage regulation, load balancing and power factor correction in distribution network [4].

Recently, multilevel inverters are used to realize the DSTATCOM [5]. There exist several types of multilevel inverters: cascaded $\mathrm{H}$ bridge, diode clamped, flying capacitors [6]. The advantages of multilevel inverters are: less harmonic content, induces good power quality,

\footnotetext{
This paper is an extended version of the paper called "Design and simulation of five-level inverter based DSTATCOM using fuzzy logic", published in the $6^{\text {th }}$ International Renewable Energy Congress (IREC), 2015 pages: 1-6, DOI: 10.1109/IREC.2015.7110875. In the current paper, a novel control method based on type- 2 fuzzy systems is used to improve the power quality. The control algorithm is presented and a set of simulations is carried out in order to prove the good performances of the proposed solution. We also compared the proposed method with the work presented in the IREC 2015.
}

lower switching losses, lower voltage distortion and eliminate the use of transformers [7-9].

To improve the performance of DSTATCOM and depending on the controlled power system parameter, various control strategies have been proposed for DSTATCOM control, such as: direct/indirect current control algorithm, instantaneous reactive power control, symmetrical component method, and double loop control strategy. These control strategies use different types of controllers, such as: PI, fuzzy, neural and hybrid controllers [10-12]. In recent years, investigation of fuzzy theory application in power system control grows rapidly [13-16]. The fuzzy logic controllers have many advantages compared with conventional controllers such as: no need to accurate mathematical model, irregularities in system parameters and it is easy to be implemented.

Recently, a large volume of literature have been used Fuzzy Logic Controllers (FLC) in the control of D-STATCOM. In [17], Srinivas proposed fuzzy, PI and hybrid fuzzy-PI controllers for STATCOM, to utilize the advantages of both fuzzy and PI controllers. The control algorithm was based on the doubleloop control strategy; the desired (reference) reactive current produced by fuzzy controller, while the DC link voltage was controlled by PI controller. In [18], investigated and implemented the Fuzzy-PI control of DSTATCOM based on the double-loop control strategy. A fuzzy adjuster was added to tune the parameters of the PI controllers. In [19], a fuzzy logic based supervisory method is 
proposed to improve transient performance of the dc link. The fuzzy logic based supervisor varies the proportional and integral gains of the PI controller during the transient period immediately after a load change. In [20], a fuzzy logic STATCOM controller design with generator speed deviation and acceleration as the input. The fuzzy controller was evaluated by comparing its performance with the classical PI control. All fuzzy logic systems presented in literature for the control of D-STATCOM focus on the conventional Type-1 FLSs. However, this type has disadvantage in terms of dynamic uncertainties present at inputs, a novel concept which is called type-2 fuzzy system has been studied to improve the uncertainty handling ability. The concept of type 2 fuzzy sets was proposed by Zadeh in 1975 to overcome the limitation of Type-1 fuzzy sets to model and minimize the effect of uncertainties. Recently, studies on the Type-2 fuzzy logic systems have obtained growing attention from researchers due their ability to handle uncertainty and he have shown that it provide good solutions due to having more degrees of freedom in design aspects [21-24].

In this work, Type-1 and Type-2 fuzzy logic controllers are proposed for the control of DSTATCOM, with the aim of compensates reactive power and corrects the power factors. The power circuit of DSTATCOM contains five-level NPC inverter; gate pulses for this inverter are generated with SVM technique. The aim of the work is shows to implement DSTATCOM with control strategies in the MATLAB, Simulink using Simpower® toolbox and to verify the results; various case studies applying different loads.

\section{DSTATCOM}

The DSTATCOM is a voltage source converter based power electronic device which is connected in parallel with the distribution system, capable of generating and /or absorbing reactive power. It provides an effective solution for reactive power compensation, power factor correction and voltage regulation. The major components of a DSTATCOM are shown in Figure 1, it consists of five level voltage source converter (VSC), DC capacitor supplying the DC voltage for inverter, a filter and controller. If the output voltage of the VSC and the source voltage are equal, no reactive power delivered to the system. When the output voltage of VSC is greater than the source voltage, the DSTATCOM supplies reactive power to the grid, the DSTATCOM is in capacitive mode of operation. If the source voltage is grater than the output voltage of VSC, the DSTATCOM absorbs reactive power from the grid, the DSTATCOM is in inductive mode. The problem with two level converters based DSTATCOM is the injecting unwanted harmonics in the power grid and is limited to operate at high frequencies due to switching losses, multilevel converters have the ability to resolve this issue.

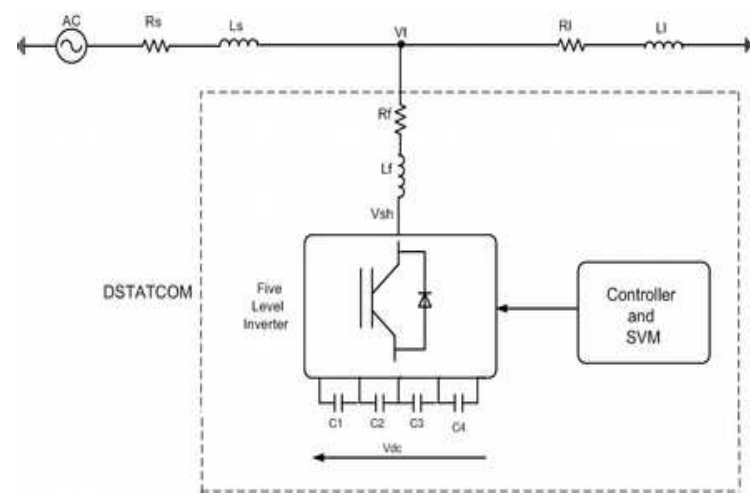

Figure 1. Schematic diagram of DSTATCOM
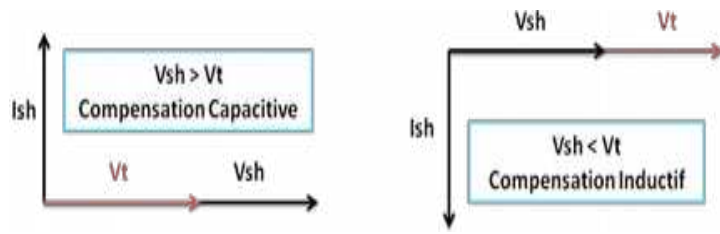

Figure 2. Operating modes of DSTATCOM

\section{Space Vector Modulation (SVM) for Five Level Inverter}

The performance of inverter is mainly depends on the switching operation. In this paper switching for the five level inverter of DSTATCOM are generated by Space Vector Modulation (SVM). SVM method has more advantages comparing to PWM technique [25]. Because it minimize harmonics, minimize switching losses and balances dc-capacitor voltages without the need of supplementary devices or additional controllers [26].

The aim of the control of the inverter is to make the output voltages va, $\mathrm{vb}$ and $\mathrm{vc}$ as close as possible to the three sinusoidal reference voltages, $v_{a}^{*}, v_{a}^{*}$ and $v_{a}^{*}$ [27]. To achieve that objective, from the reference voltage $v_{a}^{*}, v_{b}^{*}$ 


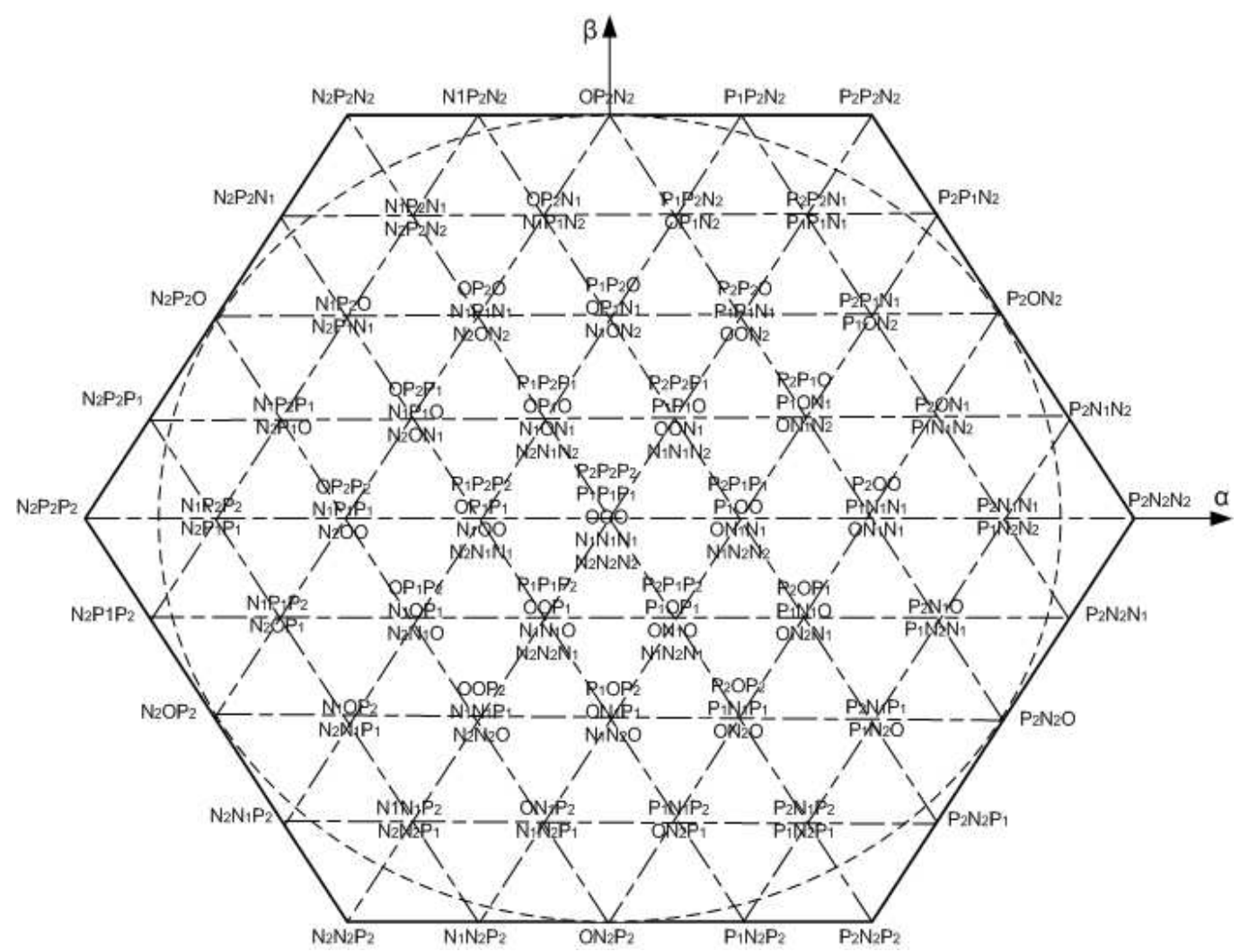

Figure 3. Hexagon showing voltage vectors of five level inverter

and $v_{c}^{*}$ we define the reference voltage vector $V^{*}$ by the following equation:

$$
V^{*}=v_{a}^{*} e^{j 0}+v_{b}^{*} e^{-j 2 \pi / 3}+v_{c}^{*} e^{j 2 \pi / 3}=v_{d}^{*}+j v_{q}^{*}
$$

Where $j$ is a complex number; equation (1) is an equation associated with the vector representation; $v_{d}^{*}$ and $v_{q}^{*}$ are the components of the vector $V^{*}$ in the plan $d-q$. This vector takes 60 discrete positions, distributed on four hexagons, in more than one position at the origin of the diagram. The position of the vector are $V^{*}$ created respectively by one, two, three or four states redundant. The position of the centre of the hexagon, which corresponds to a zero output voltage is created by five redundant statements. Thus, there are 24 positions with a single redundancy, 18 positions to two redundant, 12 positions to three redundant and 6 positions to four redundant.

\subsection{Determination of region and sector}

From the coordinates $v_{d}^{*}$ and $v_{q}^{*}$ and the angular position $q$, we deduce in what area $(s)$, and what region $(r)$ is the vector $V^{*}$ situ in the $d-q$ plane. The triangular area is derived as follows:

$$
S=\left\{\begin{array}{llr}
1 & \text { if } & 0 \leq \theta<\pi / 3 \\
2 & \text { if } & \pi / 3 \leq \theta<2 \pi / 3 \\
3 & \text { if } & 2 \pi / 3 \leq \theta<3 \pi / 3 \\
4 & \text { if } & 3 \pi / 3 \leq \theta<4 \pi / 3 \\
5 & \text { if } & 4 \pi / 3 \leq \theta<5 \pi / 3 \\
6 & \text { if } & 5 \pi / 3 \leq \theta<2 \pi
\end{array}\right.
$$

The triangular region within each sector is inferred using the equations of its three sides. For example, the sides of the region $r=1$ within the area $S=1$, have the following equations:

$$
\left\{\begin{array}{l}
v_{q}^{*}=\sqrt{3} / 4 \\
v_{q}^{*}=\sqrt{3} v_{d}^{*}-\sqrt{3} / 2 \\
v_{q}^{*}=-\sqrt{3} v_{d}^{*}+3 \sqrt{3} / 4
\end{array}\right.
$$

The vector $V^{*}$ is situated in the region $r=1$ of sector $s=1$ when the two components $v_{d}^{*}$ and $v_{q}^{*}$ satisfy the following inequalities (similarly we deduce the equations for other regions):

$$
\left\{\begin{array}{l}
v_{q}^{*} \leq \sqrt{3} / 4 \\
v_{q}^{*} \leq \sqrt{3} v_{d}^{*}-\sqrt{3} / 2 \\
v_{q}^{*} \leq-\sqrt{3} v_{d}^{*}+3 \sqrt{3} / 4
\end{array}\right.
$$


3.2 Calculating the switching times $T_{x}$, $\mathbf{T}_{\mathbf{y}}, \mathbf{T}_{\mathbf{z}}$

The switching times $T_{x}, T_{y}, T_{z}$ for any sector is given in Table I.

Table 1. Switching time duration at any Sector

\begin{tabular}{|l|l|l|}
\hline & \multicolumn{1}{|c|}{$\mathbf{T}_{\mathbf{x}}$} & \multicolumn{1}{|c|}{$\mathbf{T}_{\mathbf{y}}$} \\
\hline Region 1 & $\mathrm{T}_{\mathrm{s}} 4 \cdot \mathrm{m} \cdot \sin (\pi / 3-\alpha)$ & $\mathrm{T}_{\mathrm{s}} 4 \cdot \mathrm{m} \cdot \sin (\alpha)$ \\
\hline Region 2 & $\mathrm{T}_{\mathrm{s}}(1-4 \cdot \mathrm{m} \cdot \sin (\pi / 3-\alpha))$ & $\mathrm{T}_{\mathrm{s}}(1-4 \cdot \mathrm{m} \cdot \sin \alpha)$ \\
\hline Region 3 & $\mathrm{T}_{\mathrm{s}}(4 \cdot \mathrm{m} \cdot \sin (\pi / 3-\alpha)-1)$ & $\mathrm{T}_{\mathrm{s}} 4 \cdot \mathrm{m} \cdot \sin \alpha$ \\
\hline Region 4 & $\mathrm{T}_{\mathrm{s}}(2-4 \cdot \mathrm{m} \cdot \sin (\pi / 3-\alpha))$ & $\mathrm{T}_{\mathrm{s}}(1-4 \cdot \mathrm{m} \cdot \sin \alpha)$ \\
\hline Region 5 & $\mathrm{T}_{\mathrm{s}}(4 \cdot \mathrm{m} \cdot \sin (\pi / 3-\alpha)-2)$ & $\mathrm{T}_{\mathrm{s}} 4 \cdot \mathrm{m} \cdot \sin \alpha$ \\
\hline Region 6 & $\mathrm{T}_{\mathrm{s}}(3-4 \cdot \mathrm{m} \cdot \sin (\pi / 3-\alpha))$ & $\mathrm{T}_{\mathrm{s}}(1-4 \cdot \mathrm{m} \cdot \sin \alpha)$ \\
\hline Region 7 & $\mathrm{T}_{\mathrm{s}}(4 \cdot \mathrm{m} \cdot \sin (\pi / 3-\alpha)-1)$ & $\mathrm{T}_{\mathrm{s}} 4 \cdot \mathrm{m} \cdot \sin \alpha$ \\
\hline Region 8 & $\mathrm{T}_{\mathrm{s}} 4 \cdot \mathrm{m} \cdot \sin (\pi / 3-\alpha)$ & $\mathrm{T}_{\mathrm{s}}(4 \cdot \mathrm{m} \cdot \sin \alpha-1)$ \\
\hline Region 9 & $\mathrm{T}_{\mathrm{s}}(1-\mathrm{m} \cdot \sin (\pi / 3-\alpha))$ & $\mathrm{T}_{\mathrm{s}}(2-\mathrm{m} \cdot \sin \alpha)$ \\
\hline Region10 & $\mathrm{T}_{\mathrm{s}}(4 \cdot \mathrm{m} \cdot \sin (\pi / 3-\alpha)-1)$ & $\mathrm{T}_{\mathrm{s}}(4 \cdot \mathrm{m} \cdot \sin \alpha-1)$ \\
\hline Region11 & $\mathrm{T}_{\mathrm{s}}(2-4 \cdot \mathrm{m} \cdot \sin (\pi / 3-\alpha))$ & $\mathrm{T}_{\mathrm{s}}(2-4 \cdot \mathrm{m} \cdot \sin \alpha)$ \\
\hline Region12 & $\mathrm{T}_{\mathrm{s}}(4 \cdot \mathrm{m} \cdot \sin (\pi / 3-\alpha)-2)$ & $\mathrm{T}_{\mathrm{s}}(4 \cdot \mathrm{m} \cdot \sin \alpha-1)$ \\
\hline Region13 & $\mathrm{T}_{\mathrm{s}} 4 \cdot \mathrm{m} \cdot \sin (\pi / 3-\alpha)$ & $\mathrm{T}_{\mathrm{s}}(4 \cdot \mathrm{m} \cdot \sin \alpha-2)$ \\
\hline Region14 & $\mathrm{T}_{\mathrm{s}}(1-4 \cdot \mathrm{m} \cdot \sin (\pi / 3-\alpha))$ & $\mathrm{T}_{\mathrm{s}}(3-4 \cdot \mathrm{m} \cdot \sin \alpha)$ \\
\hline Region15 & $\mathrm{T}_{\mathrm{s}}(4 \cdot \mathrm{m} \cdot \sin (\pi / 3-\alpha)-1)$ & $\mathrm{T}_{\mathrm{s}}(4 \cdot \mathrm{m} \cdot \sin \alpha-2)$ \\
\hline Region16 & $\mathrm{T}_{\mathrm{s}} 4 \cdot \mathrm{m} \cdot \sin (\pi / 3-\alpha)$ & $\mathrm{T}_{\mathrm{s}}(4 \cdot \mathrm{m} \cdot \sin \alpha-3)$ \\
\hline
\end{tabular}

\subsection{Finding the switching states}

Because of the redundant voltage vectors of each state, there are several options to determine the switching sequence. Switching sequence can be arranged according to certain optimal objective, for example, minimize losses in the inverter and reduce harmonics of the output voltage [28]. In this paper, in order to achieve low THD and to reduce harmonics of the output voltage a sequence of states is selected which is to:

- apply the three states in a given order during the half period, then in the reverse order for the remainder of the period;

- divide the appropriate time to each state on any redundancies;

- use the same state at the

- beginning and the end of the sampling period.

\section{DSTATCOM Control}

The control of DSTATCOM is schematically depicted in Figure 7. For the proposed control strategy of this paper, real and reactive power exchange between the DSTATCOM and the AC system are controlled by regulating the two current components $i_{d}$ and $i_{q}$. In the control circuit two regulators are found; one is the current regulators and the other is the DC voltage regulator. Both regulators are of Type-1 or Type-2 fuzzy logic controller. Switching pulses for the five levels inverter are generated by SVM technique which is gives a good response. For the control of DC voltage of the DSTATCOM a fuzzy logic controller generates the reference signal of the d-axis current $i_{d}^{*}$. The main objective of this control algorithm is reactive power compensation and power factor correction, therefore $i_{q}^{*}$ is only the imaginary

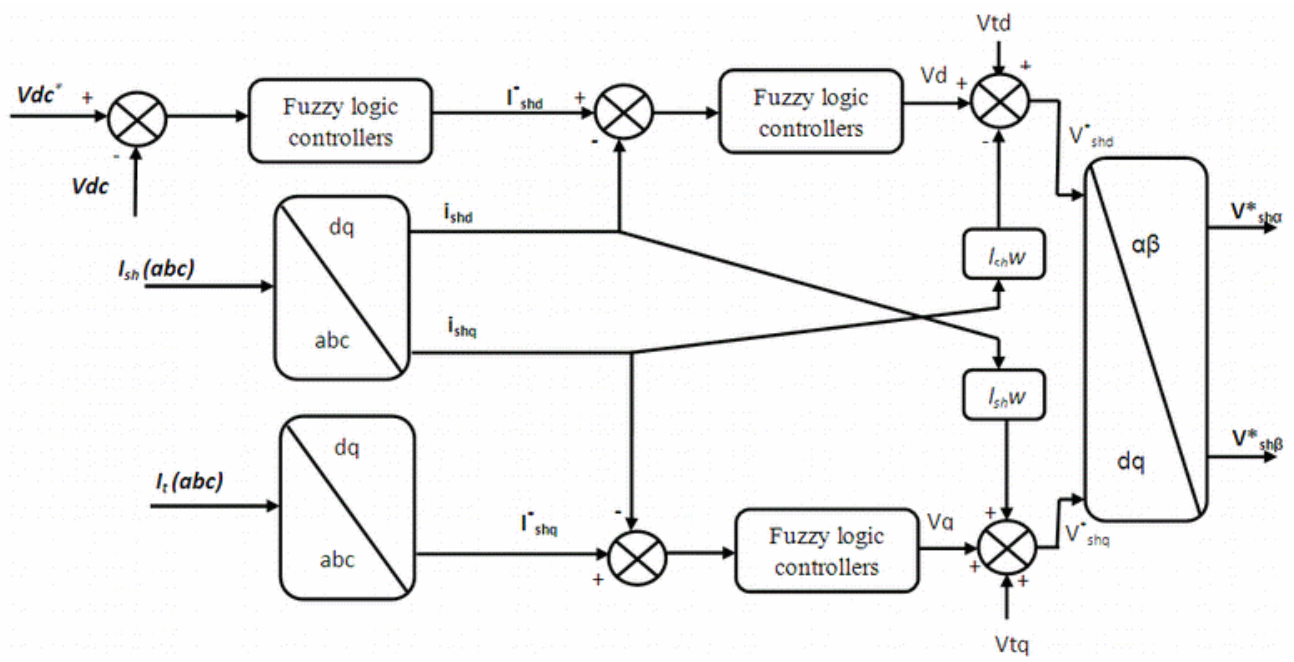

Figure 7. Control unit of DSTATCOM 
component of the current load [29]. The outputs of the current regulator $v_{d}^{*}$ and $v_{q}^{*}$ are the reference voltages necessary for the SVM block. To enhance the transient stability AC power system, Type-1 and Type-2 fuzzy logic controllers are adopted for the control of the DSTATCOM, in this work The performance of the DSTATCOM is studied for power compensation and power factor correction through the regulation of currents components using type- 1 and type- 2 fuzzy logic controllers.

\subsection{Type-1 Fuzzy Logic Controller}

Fuzzy logic controllers are widely used in controlling disturbances in power systems. The advantages of FLCs over conventional controllers are that not sensitive to system topology, does not require the knowledge of the mathematical model of the system and they can work with imprecise inputs [30-31]. Type-1 FLC is shown in Figure 4. The fuzzy logic controller is composed of four stages which are: fuzzification, rules of fuzzy control, the inference and the defuzzification [32]. The fuzzy controller of Figure 4 is introduced like a system at two inputs and an output. The control input variables for the proposed type-1 FLC are chosen as error $e(i)$ and variation of the error $\Delta e(i)$ :

$$
\left\{\begin{array}{l}
e(i)=Y_{r e f}-Y(i) \\
\Delta e(i)=e(i)-e(i-1)
\end{array}\right.
$$

Membership functions representing input and output variables are given by Figure 5. In our case we considered the case of seven sets represented by functions of memberships in triangular form: NB (Negative big), NM (Negative Medium), NS (Negative small), ZR (Zero), PS (Positive Small), PM (Positive medium), and PB (Positive big).

The fuzzy control rule is illustrated in the Table 2. There are total 49 rules used for achieving the desired performance of system. The method of inference selected is Mamdani method considering which it is easy to establish. In the defuzzification process where the output of the fuzzy sets is transferred into identifiable value, the centre of gravity method is used, the output of the FLC is then written as: [33]

$$
X_{R}^{*}=\Delta U=\sum_{i=1}^{m} \frac{\mu_{C E i} X^{*} E i}{\mu_{C E i}}
$$

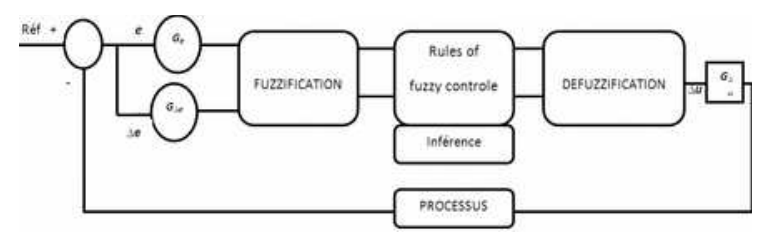

Figure 4. Structure interns of a regulator by fuzzy logic

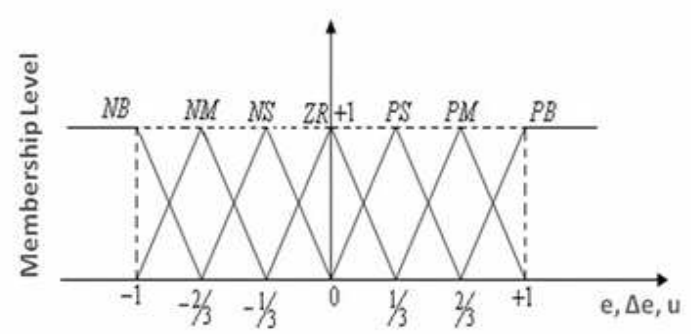

Figure 5. Distribution of the functions of membership according to the triangular form

Table. 2 Rules for T1 FLS

\begin{tabular}{|c|c|c|c|c|c|c|c|}
\hline \multicolumn{1}{|r}{$\mathbf{e}$} & $\mathbf{N B}$ & $\mathbf{N M}$ & $\mathbf{N S}$ & $\mathbf{Z R}$ & $\mathbf{P S}$ & $\mathbf{P M}$ & $\mathbf{P B}$ \\
\hline NB & NB & NB & NB & NB & NM & NS & ZR \\
\hline NM & NB & NB & NB & NM & NS & ZR & PS \\
\hline NS & NB & NB & NM & NS & ZR & PS & PM \\
\hline ZR & NB & NM & NS & ZR & PS & PM & PB \\
\hline PS & NM & NS & ZR & PS & PM & PB & PB \\
\hline PM & NS & ZR & PS & PM & PB & PB & PB \\
\hline PB & ZR & PS & PM & PB & PB & PB & PB \\
\hline
\end{tabular}

\subsection{Type-2 Fuzzy Logic Controller:}

In recent years type-2 FLCs have become increasingly popular due to their ability to cope with uncertainties. The type-2 FLC uses type-2 fuzzy sets to represent the inputs and/or outputs of the controller; the concept of these type-2 fuzzy sets was introduced by Zadeh as an extension of the concept of type-1 fuzzy sets [34]. The type-2 fuzzy set is characterized by a three dimensional membership function and includes a Footprint Of Uncertainty (FOU); the third dimension provides an additional level of freedom for the inclusion of linguistic uncertainties using type-2 membership function. The type-2 FLC has the same configuration as that of type-1 FLC; the use of this type-2 control requires an additional operation which is the type reduction. There are five fundamental stages in a type-2 FLC: Fuzzification, Rule base, Inference system, Type reduction and Defuzzification. In last day the majority of the control applications of type2 fuzzy logic have used interval type-2 fuzzy 
logic, due to the facilitating the design of controllers and simplifying the computation. Interval type-2 FLS is a special case of general type-2 FLS when the input/ output domains are characterized by interval type- 2 sets [35].

In this paper, interval type-2 FLS is employed, the Figure 8 show the structure of interval type2 fuzzy systems (IT2FS). The variables indexed norm are the normalized variables, the gains at the controller are to be determined by adjusting in order to have the desired response.

\subsection{Fuzzification:}

In this stage the measured inputs transformed into fuzzy linguistic values (type2-fuzzy set). The input and output variables are extended to the interval type-2 triangular membership functions, each input/ output variable has same seven linguistic variables named as: NB (Negative big), NM (Negative Medium), NS (Negative small), ZR (Zero), PS (Positive Small), PM (Positive medium), PB (Positive big). All membership functions for the IT2FLC inputs (e and $\Delta \mathrm{e}$ ) and the controller output (u) are defined on the common normalized domain $[-1,1]$ which are defined in Figure 6.

\subsection{Rule base:}

The fuzzy rules of interval type-2 fuzzy system are still remained the same as in type- 1 fuzzy system but the antecedents and the consequents will be represented by interval type-2 fuzzy sets. In the present model 49 rules are developed (Table 3), and these rules can be written as:

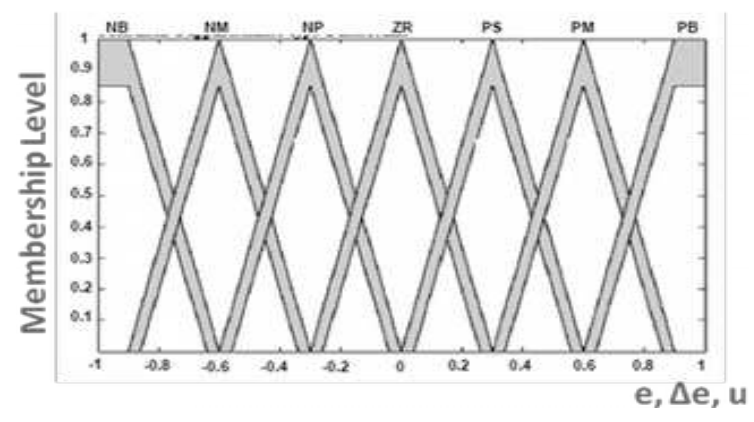

Figure 6. Type-2 membership grades for e, $\Delta \mathrm{e}$ and $\mathrm{u}$

$\mathrm{R}^{\mathrm{i}}$ : IF $\mathrm{x}_{1}$ is $\mathrm{F}_{1}^{\mathrm{i}}$ and $\mathrm{x}_{2}$ is $\mathrm{F}_{2}^{\mathrm{i}} \ldots \ldots$ and $\mathrm{x}_{\mathrm{n}}$ is $\mathrm{F}_{\mathrm{n}}^{\mathrm{i}}$ THEN $y^{i}=G^{i},(i=1, \ldots \ldots, n)$.

Where $x^{i}$ and $y^{i}$ are the input and output of the ith rule $R^{i}, F_{1 \ldots \ldots .}^{i} F_{n}^{i}$ are antecedent linguistic terms that are modeled by interval type- 2 fuzzy sets.

Table 3. Rule Base

\begin{tabular}{|c|c|c|c|c|c|c|c|}
\hline \multicolumn{1}{|c|}{$\mathbf{e}$} & NG & NM & NS & EZ & PP & PM & PG \\
\hline NG & NG & NG & NG & NM & NP & NP & EZ \\
\hline NM & NG & NM & NM & NM & NP & EZ & PP \\
\hline NP & NG & NM & NP & NP & EZ & PP & PM \\
\hline EZ & NG & NM & NP & EZ & PP & PM & PG \\
\hline PP & NM & NP & EZ & PP & PP & PM & PG \\
\hline PM & NP & EZ & PP & PM & PM & PM & PG \\
\hline PG & EZ & PP & PP & PM & PG & PG & PG \\
\hline
\end{tabular}

\subsection{Inference system:}

In this stage the process consists of combining the fuzzy rules and mapping the crisp inputs to the interval type- 2 fuzzy output sets. The result of the inference engine is a type- 2 fuzzy set.

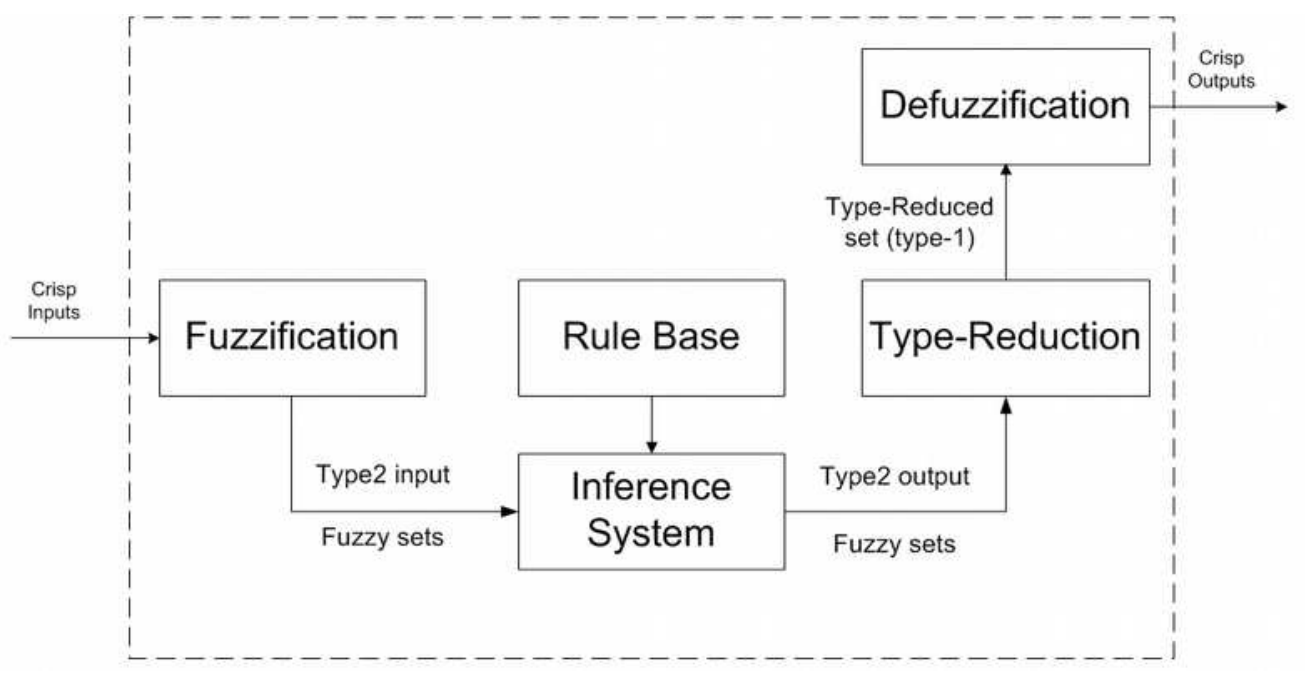

Figure 8. Type-2 Fuzzy Inference System 


\subsection{Type reduction and Defuzzification:}

In the type reduction stage, the interval type2 fuzzy outputs of the inference engine are mapped to interval type-1 fuzzy set in order to perform the defuzzification. The type reduction block is main difference between type- 1 and type- 2 fuzzy logic system. The type reduced set of the interval type- 1 set $\left[y_{l}, y_{r}\right]$, where indexed 1 and $\mathrm{r}$ indicate left and right limits. There are different types of type reduction methods. Center of Sets (COS) type reduction is most widely used, that is developed by Karnik and Mendel and can be expressed as [36]:

$$
\begin{aligned}
& Y_{\cos }(x)=\left[y_{l}, y_{r}\right]= \\
& \int_{y^{1} \in\left[y_{1}^{1}, y_{r}^{1}\right]} \ldots \ldots . \int_{y^{M} \in\left[y_{l}^{M}, y_{r}^{M}\right]} \int_{f^{1} \in\left[f_{l}^{1}, f^{1}\right]} . \\
& \ldots . \int_{f^{M} \in\left[f_{l}^{M}, f^{M}\right]} \frac{1}{\sum_{i=1}^{M} f^{i} y^{i} / \sum_{i=1}^{M} f^{i}}
\end{aligned}
$$

Where $Y_{\cos }$ is the interval set determined with its left limit $Y_{l}$, and its right limit $Y_{r}$. And $i=1, \ldots \ldots M$ represent the number of rules. $Y_{l}$ and $Y_{r}$ can be expressed as:

$$
y_{l}=\frac{\sum_{i=1}^{M} f_{l}^{i} y_{l}^{i}}{\sum_{i=1}^{M} f_{l}^{i}}=y_{r}=\frac{\sum_{i=1}^{M} f_{r}^{i} y_{r}^{i}}{\sum_{i=1}^{M} f_{r}^{i}}
$$

After the type reduction process, the type reduced sets are defuzzified to obtain the crisp output. We defuzzify the set obtained from type reducer by using the average of $Y_{l}$ and $Y_{r}$ [37], so the defuzzified output is:

$y=\frac{y_{l}+y_{r}}{2}$

\section{Simulation Results}

In this study, the model of power system, DSTATCOM and controller are developed in MATLAB/Simulink environment and shown in Figure 9. Type-1 and type-2 fuzzy logic controllers were used for controlling DSTATCOM. The performance of DSTATCOM is studied in a power system. The distribution part of the power system is represented by a Thevenin's equivalent voltage source and short circuit impedance. The operation of the DSTATCOM device in a electric power transmission line will be validated in the two modes of capacitive and inductive compensation.

Initially the DC bus capacitor is charged and the voltage across the latter is $20 \mathrm{kV}$. At the beginning of the simulation, the grid supplies the load (L1). The second charge (L2) is connected to the grid at time $(\mathrm{t}=0.25 \mathrm{~s})$, and at time $(\mathrm{t}=0.5 \mathrm{~s})$ line is loaded by load (L3), and finally at time $(\mathrm{t}=0.75 \mathrm{~s})$ both load (L1) and (L2) is Logged Out. The simulation diagram, shown in Figure 9, is used to simulate the DSTATCOM operation for different loads. All the relevant outputs are shown in Figure 10 to Figure 15.

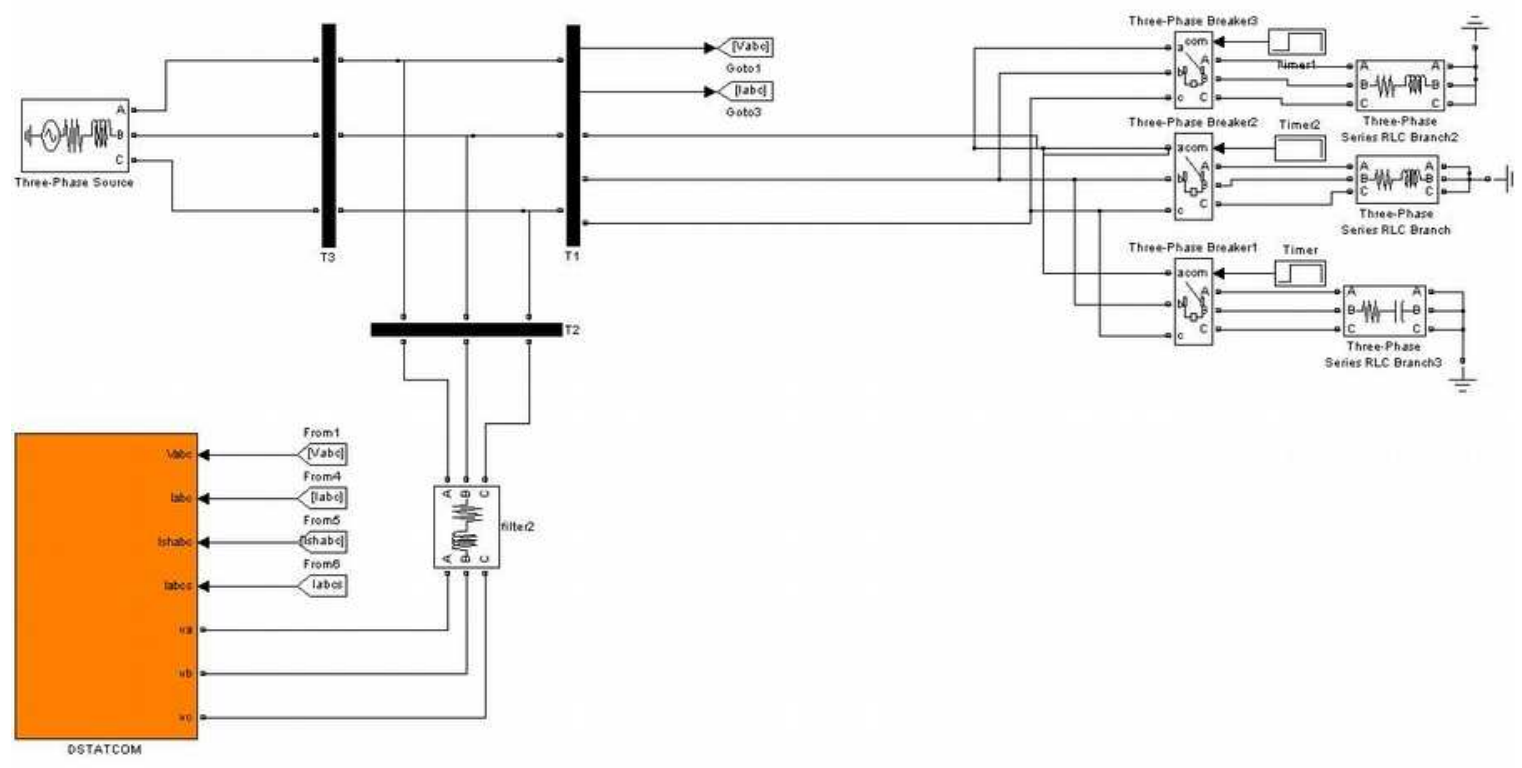

Figure 9. DSTATCOM simulation in MATLAB 
The index ' $a$ ' and ' $b$ ' are referred to the results obtained by the type-1 FLC and type2 FLC respectively.

The capacitor voltage is maintained at $20 \mathrm{kV}$ as shown in Figure 10. Figure 11 shows the dynamics of reactive current exchanged between the DSTATCOM and network, initially the electrical source feeds an inductive load therefore the reactive current is negative and the DSTATCOM operate in inductive mode (DSTATCOM delivers reactive power), when we charge the network by the capacitive load the reactive current becomes positive and the DSTATCOM Operate in capacitive mode (DSTATCOM absorbs reactive power). The active current exchanged between the DSTATCOM and network as shown in Figure 12. Figure 13 shows the dynamics of active and reactive power of network, the reactive component is always zero, which shows that the DSTATCOM compensate all of the reactive power required by the load and therefore, it achieve unity power factor operation source side, this is evidenced by the Figure 14 which

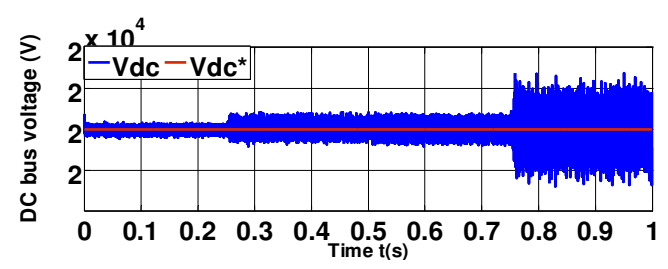

(a) represents the improvement of power factor with DSTATCOM. The active and reactive power injected by DSTATCOM as shown in Figure 15.

\section{Comparative Analysis of the Results}

In the aim to simulate the impact of the measurement uncertainty on the performance of type- 1 and type- 2 fuzzy logic controllers, a white noise with normal distribution is added to the measurement values of DC voltage, active and reactive currents.

Three widely used performance criteria are used [38], for comparison between type-1 and type-2 fuzzy logic controllers, these are: integral of square error (ISE), integral of the absolute value of the error (IAE), and integral of the time multiplied by the absolute value of the error (ITAE). The Table. 4 summarizes the values obtained for each criterion for simulation time $\left(\begin{array}{ll}1 & s\end{array}\right)$. The values of measurement Uncertainty of both controllers are shown in Table 4, the results confirm that

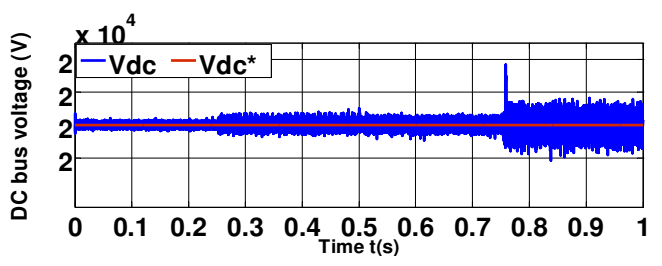

(b)

Figure 10. Variation of DC bus voltage

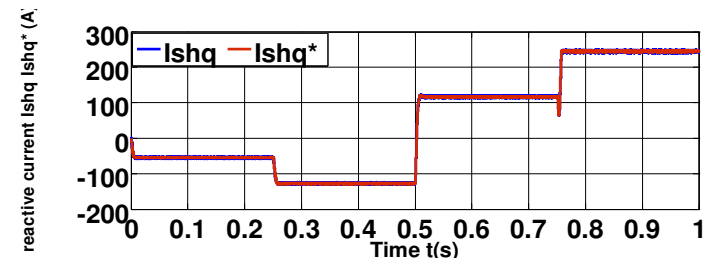

(a)

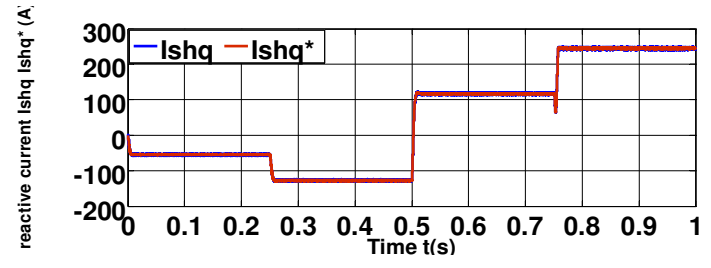

(b)

Figure 11. The reactive current injected by the DSTATCOM

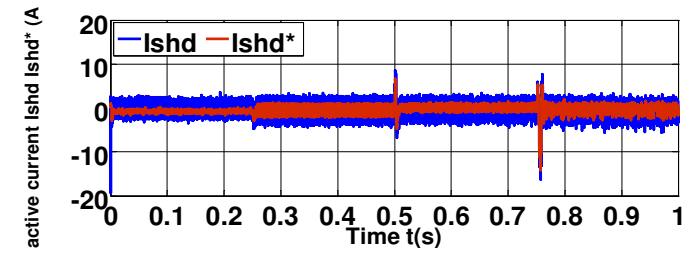

(a)

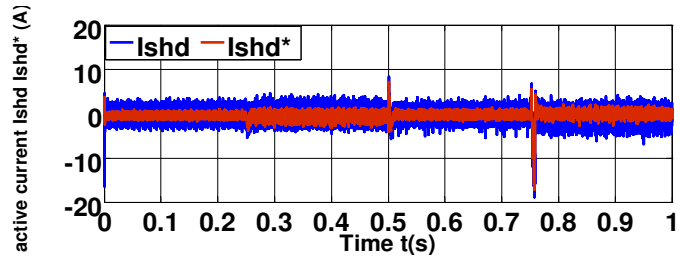

(b)

Figure 12. The active current injected by the DSTATCOM 


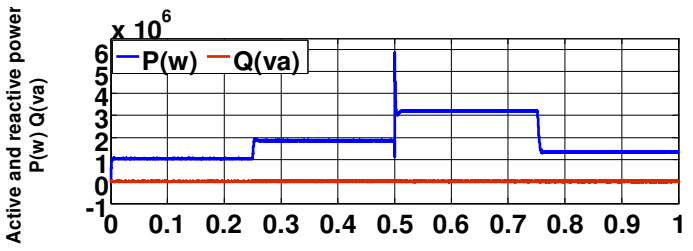

(a)

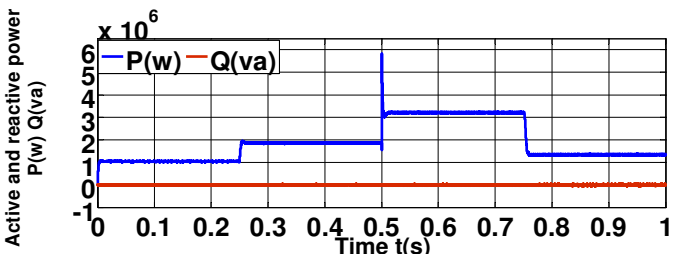

(b)

Figure 13. The active and reactive power of network

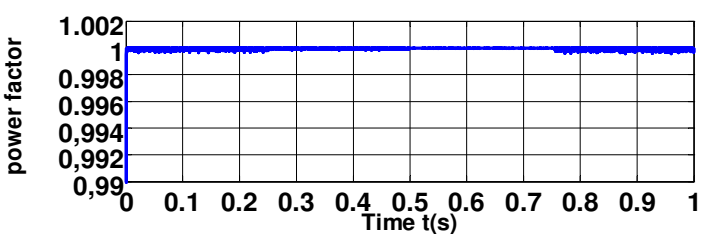

(a)

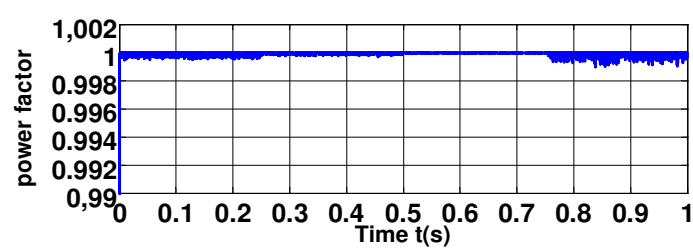

(b)

Figure 14. Power factor

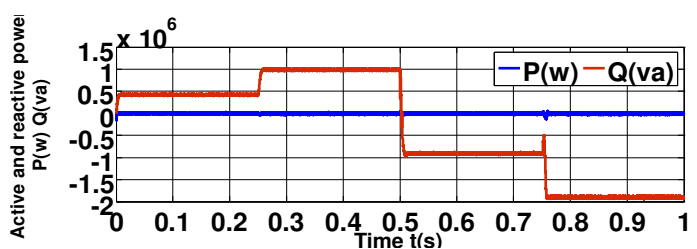

(a)

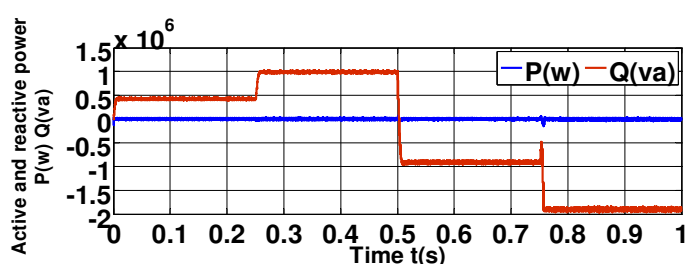

(b)

Figure 15. The active and reactive power injected by DSTATCOM

Table 4. Performance criteria values for type-1 and type-2 FLCs

\begin{tabular}{|c|c|c|c|}
\hline & & & $\begin{array}{c}\text { Measurement } \\
\text { Uncertainty }\end{array}$ \\
\hline \multirow{6}{*}{$\underline{\underline{2}}$} & \multirow{2}{*}{ DC voltage } & T1FLC & 81374 \\
\hline & & T2FLC & 80306 \\
\hline & \multirow{2}{*}{$\begin{array}{l}\text { Active } \\
\text { current }\end{array}$} & T1FLC & 97842 \\
\hline & & T2FLC & 90808 \\
\hline & \multirow{2}{*}{$\begin{array}{l}\text { Reactive } \\
\text { current }\end{array}$} & T1FLC & 121240 \\
\hline & & T2FLC & 120890 \\
\hline \multirow{6}{*}{ 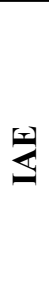 } & \multirow{2}{*}{ DC voltage } & T1FLC & 104180 \\
\hline & & T2FLC & 101420 \\
\hline & \multirow{2}{*}{$\begin{array}{l}\text { Active } \\
\text { current }\end{array}$} & T1FLC & 152100 \\
\hline & & T2FLC & 137300 \\
\hline & \multirow{2}{*}{$\begin{array}{l}\text { Reactive } \\
\text { current }\end{array}$} & T1FLC & 239020 \\
\hline & & T2FLC & 235640 \\
\hline \multirow{6}{*}{ 息 } & \multirow{2}{*}{ DC voltage } & T1FLC & 40823 \\
\hline & & T2FLC & 40197 \\
\hline & \multirow{2}{*}{$\begin{array}{l}\text { Active } \\
\text { current }\end{array}$} & T1FLC & 51180 \\
\hline & & T2FLC & 47843 \\
\hline & \multirow{2}{*}{$\begin{array}{l}\text { Reactive } \\
\text { current }\end{array}$} & T1FLC & 66306 \\
\hline & & T2FLC & 64717 \\
\hline
\end{tabular}

the best system response is obtained by the usage of type-2 fuzzy logic controller, so type- 2 fuzzy logic is a good alternative to deal with systems with uncertainty.

The work carried out demonstrates that:

- The SVM strategy avoids the dc link capacitance voltage imbalance problem; simulation results allow an evaluation of the impact of the multilevel inverter based DSTATCOM.

- When noise was applied, as expected the type2 controllers were usually better than the type1 controllers, it is the new third dimension of type-2 fuzzy sets and the footprint of uncertainty that provide additional degrees of freedom that make it possible to directly model and handle uncertainties.

\section{Conclusion}

In this study, theoretical study with simulation of a T1FL and T2FL controllers for a DSTATCOM based five-level inverter in order to improve the power quality is studied. The performance of the DSTATCOM control using 
T2FL controllers is compared by simulation with that of a DSTATCOM control using T1FL controllers. The simulation results show that the both controllers achieve good control, but the performance of the IT2FLC is better than T1FLC in the presence of extreme or significant parameter variations or external disturbances, this was confirmed by the results of Table 4. The SVM method is used to generate the switching signals for the five levels inverter. MATLAB based simulation results have verified the effectiveness of the design methodology. It significantly enhances the power system stability.

\section{REFERENCES}

1. SECUI, D. K., S. DZITAC, G. V. BENDEA, I. DZITAC, An ACO Algorithm for Optimal Capacitor Banks Placement in Power Distribution Networks, Studies in Informatics and Control, vol. 18, no. 4, 2009, pp. 305-314.

2. HOOSHMAND, R., E. TORABIAN, Adaptive Filter Design Based on the LMS Algorithm for Delay Elimination in Tcr/Fc Compensators, ISA Trans 2011, vol. 50, no. 2, 2011, pp. 142-149.

3. MURUGESAN, K., R. MUTHU, S. VIJAYENTHIRAN, J. MERVIN, Prototype Hardware Realization of the DSTATCOM for Reactive Power Compensation, International Journal of Electrical Power \& Energy Systems, vol. 65, 2015, pp. 169-178.

4. SHARMA, R., P. NIJHAWAN, Effectiveness of DSTATCOM to Compensate the Load Current Harmonics in Distribution Networks under Various Operating Conditions, International Journal of Scientific Engineering and Technology, vol. 2, no. 7, 2013, pp. 713-718.

5. GAWANDE, S. P., M. R. RAMTEKE, Three-level NPC Inverter based New DSTATCOM Topologies and Their Performance Evaluation for Load Compensation, International Journal of Electrical Power \& Energy Systems, vol. 61, 2014, pp. 576-584.
6. SOTO, J. S., F. Z. PENG, Multilevel Converters-a New Breed of Power Converters, Transactions on Industry Applications, IEEE, vol. 32, no. 3, 1996, pp. 509-517.

7. SHUKLA, A., A. GHOSH, A. JOSHI, State Feedback Control of Multilevel Inverters for DSTATCOM Applications, Power Delivery, IEEE Transactions on, vol. 22, no. 4, 2007, pp. 2409-2418.

8. SOTO, D., J. BORQUEZ, Control of a Modular Multilevel Matrix Converter for High Power Applications, Studies in Informatics and Control, vol. 21, no. 1, 2012, pp. 85-92.

9. DALESSANDRO, L., S. D. ROUND, J. W. KOLAR, Center-point Voltage Balancing of Hysteresis Current Controlled Threelevel PWM Rectifiers, Power Electronics, IEEE Transactions on, vol. 23, no. 5, 2008, pp. 2477-2488.

10. SINGH, B., S. K. DUBE, S. R. ARYA, An Improved Control Algorithm of DSTATCOM for Power Quality Improvement, International Journal of Electrical Power \& Energy Systems, vol. 64, 2015, pp. 493-504.

11. AJAMI, A., N. TAHERI, A Hybrid Fuzzy/LQR Based Oscillation Damping Controller Using 3-level STATCOM, International Journal of Computer Electronics Engineering, vol. 3, no. 2, 2011, pp. 184-189.

12. MARIUN, N., H. HIZAM, A. W. N. IZZRI, Design of the Pole Placement Controller for D-STATCOM in Mitigating Three Phase Fault, Power Engineering Society Inaugural Conference and Exposition in Africa, 2005 IEEE, 2005, pp. 349-355.

13. GUPTA, A., P. R. SHARMA, Design and Simulation of Fuzzy Logic Controller for DSTATCOM in Power System, International Journal of Engineering Science and Technology, vol. 3, no. 10, 2011, pp. 7815-7822.

14. HAFAIFA, A., F. LAAOUAD, K. LAROUSSI, Fuzzy Approach Applied in Fault Detection and Isolation to the Compression System Control, Studies in 
Informatics and Control, ICI Publishing House, vol. 19, no1, 2010, pp. 17-26.

15. MIKKILI, S., A. K. PANDA, Real-time Implementation of PI and Fuzzy Logic Controllers based Shunt Active Filter Control Strategies for Power Quality Improvement, International Journal of Electrical Power \& Energy Systems, vol. 43, no. 1, 2012, pp. 1114 - 1126.

16. SAAD, S., L. ZELLOUMA , Fuzzy Logic Controller for Three-level Shunt Active Filter Compensating Harmonics and Reactive Power, Electric Power Systems Research, vol. 79, no. 10, 2009, pp. 1337-1341.

17. SRINIVAS, K. V., B. SINGH, A. CHANDRA, New Control Strategy of Two-Level 12-Pulse VSCs Based Statcom Using Hybrid Fuzzy-PI Controller, Indian Institute of Technology, 2010.

18. CHATterJeE, S. A., K. D. JOSHI, A Comparison of Conventional, DirectOutput-Voltage and Fuzzy-PI Control Strategies for D-STATCOM, in Modern Electric Power Systems, 2010, pp. 1-6.

19. KUMAR, N. M. G., P. S. RAJU, P. VENKATESH, Control of DC Capacitor Voltage in a DSTATCOM using Fuzzy Logic Controller, Int. Journal of Advances in Engineering \& Technology, 2012.

20. RAHIM, A. H. M. A., S. A. AL-BAIYAT, M. F. KANDLAWALA, A Fuzzy STATCOM Control for power System Damping Enhancement, In: 2nd IEEEGCC conference IEEE-GCC Conference, 2004, pp. 463-467.

21. BARKAT, S., A. TLEMÇANI, H. NOURI, Noninteracting Adaptive Control of PMSM using Interval Type-2 Fuzzy Logic Systems, Fuzzy Systems, IEEE Trans., vol. 19, no. 5, 2011, pp. 925-936.

22. HAGRAS, H., Type-2 FlCs: a New Generation of Fuzzy Controllers, Computational Intelligence Magazine, IEE, vol. 2 , no. 1,2007 , pp. $30-34$.

23. KARNIK, N. N., J. M. MENDEL, Q. LIANG, Type-2 Fuzzy Logic Systems, Fuzzy Systems, IEEE Transactions on, vol. 7, no. 6, 1999, pp. 643-658.
24. PANDA, M. K., G. PILLAI, V. KUMAR, An Interval Type-2 Fuzzy Logic Controller for TCSC to Improve the Damping of Power System Oscillations, Frontiers in Energy, vol. 7, no. 3, 2013, pp. 307-316.

25. JUNG, J. W., Space Vector PWM Inverter, Dept. of Electrical and Computer Engineering, Ohio State University.

26. RATHNAKUMAR, D., J. LAKSHMANA PERUMAL, T. SRINIVASAN, A New Software Implementation of Space Vector PWM, SoutheastCon, IEEE Proceedings, 2005.

27. LALILI, J., N. LOURCI, E. M. BERKOUK, F. PETZOLDT, M. Y. DALI, A Simplified Space Vector Pulse Width Modulation Algorithm for Five Level Diode Clamping Inverter, Power Electronics, Electrical Drives, Automation and Motion, SPEEDAM 2006. International Symposium on. IEEE, 2006, pp. 1349-1354.

28. HU, H., W. YAO, Z. LU, Design and Implementation of Three-level Space Vector PWM IP Core for FPGAs, Power Electronics, IEEE Transactions on, vol. 22, no. 6,2007 , pp. 2234-2244.

29. LI, Y., B. WU, A Novel DC Voltage Detection Technique in the CHB Inverter-based STATCOM, Power Delivery, IEEE Transactions on, vol. 23, no. 3, 2008, pp. 1613-1619.

30. LEE, T. S., K. S. TZENG, M. S. CHONG, Fuzzy Iterative Learning Control for Three-phase Shunt Active Power Filters, Industrial Electronics, IEEE International Symposium on, vol. 2, 2006, pp. 882-885.

31. JAIN, S. K., P. AGRAWAL, H. O. GUPTA, Fuzzy Logic Controlled Shunt Active Power Filter for Power Quality Improvement, IEE Proceedings-Electric Power Applications, vol. 149, no. 5, 2002, pp. 317-328.

32. MENDEL, J.M., Uncertain Rule-Based Fuzzy Logic Systems: Introduction and New Directions, Prentice Hall, 2001. 
33. BULER, H., Règles par logique floue, Presse polytechnique romandes, vol. 2, Suisse, 1994.

34. ZADEH, L. A., The Concept of a Linguistic Variable and Its Application to Approximate Reasoning, Information Sciences, vol. 08, 1975, pp. 199-249.

35. LIANG, Q., J. M. MENDEL, Interval Type-2 Fuzzy Logic Systems: Theory and Design, Fuzzy Systems, IEEE Transactions on, vol. 08, no. 05, 2000, pp. 535-550.
36. MENDEL, J. M., R. I. B. JOHN, Type-2 Fuzzy Sets Made Simple, Fuzzy Systems, IEEE Transactions on, vol. 10, no. 02, 2002, pp. 117-127.

37. MENDEL, J. M., Uncertain Rule-based Fuzzy Logic System: Introduction and New Directions, 2001.

38. CAStillo, O., Type-2 Fuzzy Logic in Intelligent Control Applications, Heidelberg: Springer, vol. 272, 2012. 